Voix et Images

voixetimages

\title{
La pensée critique en noir et blanc
}

\section{Jean Fisette}

Volume 13, numéro 3 (39), printemps 1988

Jack Kerouac et l'imaginaire québécois

URI : https://id.erudit.org/iderudit/200737ar

DOI : https://doi.org/10.7202/200737ar

Aller au sommaire du numéro

Éditeur(s)

Université du Québec à Montréal

ISSN

0318-9201 (imprimé)

1705-933X (numérique)

Découvrir la revue

Citer cet article

Fisette, J. (1988). La pensée critique en noir et blanc. Voix et Images, 13(3), 483-488. https://doi.org/10.7202/200737ar d'utilisation que vous pouvez consulter en ligne.

https://apropos.erudit.org/fr/usagers/politique-dutilisation/ 


\title{
La pensée critique en noir et blanc
}

\author{
par Jean Fisette, Université du Québec à Montréal
}

\begin{abstract}
Ah ah ah ah ah ah ah ah ah!!! Ne sais-tu pas reconnaitre l'ironie d'un discours qui s'emballe? Et ne connais-tu pas le délire parmi les instruments du vrai penseur? (p. 114)
\end{abstract}

En donnant à son recueil d'essais critiques le titre de la Petite Noirceur 1 , Jean Larose inscrivait déjà tout un programme de lecture, la «noirceur» superposant l'image des années quatre-vingts sur celles des années duplessistes, alors que le terme "petite» vient amoindrir cette métaphore au point de la donner comme dérisoire. Cet effet réthorique d'évaluation/dévaluation reviendra constamment au cours de cet ouvrage. Et pourtant, le sujet est loin d'être dérisoire: ce dont il est ici question, c'est de la définition et des conditions d'existence de la culture au Québec, de sa relation au projet national «avorté», du silence des intellectuels suite à l'échec référendaire. Et, d'une certaine façon, tous ces essais ne parlent que des «d́́combres» culturels sur lesquels s'ouvrait la décennie.

La question qui se pose alors est la suivante: comment l'intellectuel trouvera-t-il à se définir face à cette situation? Baudrillard affirme que l'un des traits qui caractérisent la société de masse est non pas qu'elle s'impose le silence, mais bien qu'elle interdit qu'il soit parlé en son nom ${ }^{2}$. La collectivité québécoise avait répondu à la question référendaire précisément dans cette logique de «masse sociale».

Il s'ensuit que le tournant des années quatre-vingts a forcé l'intellectuel à se rapprocher des gens, à les écouter plutôt qu'à parler en leur nom. Quoi qu'on ait pu en dire, les intellectuels ne se sont pas tus; au contraire, ils ont beaucoup parlé; mais ils ont parlé de l'événement, tout près, la plupart du temps en privé, cherchant à le comprendre, à en tirer une signification, à se situer par rapport à lui. Jean Larose, quant à lui, a publié ses réflexions sous forme d'essais, de 
critiques ponctuelles, dans le cadre d'une énonciation où le sujet assume sa subjectivité d'énonciateur. On ne trouve plus un «je» qui parle au nom du «nous», mais bien un «je» qui parle du «nous» collectif.

Ce recueil d'essais en témoigne de façon éloquente et nul doute qu'il illustre au mieux cette position qui a été faite à l'intellectuel de devoir retarder, reporter à plus tard la reconstruction symbolique du collectif.

Mais l'intellectuel accepte mal qu'on lui impose le silence, l'écoute, d'où peut-être l'effet de dérision engendré par ce titre.

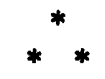

Les essais ici rassemblés ont été destinés à divers médias, dans des circonstances spécifiques: réponse à une enquête de Lise Bissonnette sur la culture québécoise; une participation à un numéro thématique de la revue Liberté (à laquelle est attaché l'auteur) consacré aux productions télévisuelles, deux interventions radiophoniques (à Radio-Canada) sur les campagnes référendaires, des chroniques sur divers sujets tels «La pensée de Léandre Bergeron», le Déclin de l'empire américain, Maria Chapdelaine, le défilé national de la saint-Jean-Baptiste, et un long texte critique sur le numéro thématique que la revue Voix \& images avait consacré à la Nouvelle Barre du jour ${ }^{3}$; enfin, un texte inédit, «Si tu reviens au Canada... Lettre à une amie», placé en postface, constitue une synthèse des débats tenus depuis six ans et ici repris.

Les objets traités peuvent se ramener à deux classes suivant une catégorie que propose Larose lui-même: ceux qui relèvent d'une culture populaire (comme la production télévisuelle) et ceux qui appartiennent à la culture savante (comme la revue la Nouvelle Barre du jour). Cette schématisation nous conduit au cœur de la problématique qui sous-tend ces essais, assurant une cohésion à l'ouvrage.

Culture savante et culture populaire renvoient à deux conceptions tout à fait divergentes. Il s'agit, dans un cas, d'une saisie anthropologique où l'habitude la plus quotidienne, le geste le plus banal autant que le rituel le plus significatif sont reconnus comme phénomènes ethnologiques participant à la configuration générale de l'ethnie. A l'opposé, on a à fairo à une définition plus classique de la culture prise au sens strict, suivant laquelle, à la limite, dans une société, seuls les membres de l'intelligentsia auraient légitimement droit de parole.

Pour saisir l'enjeu de ces essais, il faut bien reconnaître et comprendre que ces deux parcours s'entrecroisent constamment, provoquant les effets de sens les plus hallucinants. On l'a vu, la diversité des objets pris en considération nous renvoie à une conception anthropologique de la culture. Mais lorsque Larose, commentant un dossier de Voix \& images, inscrit un procès contre la Nouvelle Barre du jour, lui reprochant le mimétisme aveugle d'un savoir parisien 
mal digéré (la modernité parisieñne ici transplantée, p. 160), il se réfêre en fait à un manque d'enracinement dans la culture d'ici. Inversement, lorsqu'il reproche à la Nouvelle Barre du jour une totale incapacité de distanciation critique par rapport à elle-même (Á force de concevoir la critique comme un art «réverbérant», ils ont perdu toute ressource critique, mais ni les unes ni les autres ne semblent capables de s'en apercevoir, p. 171), c'est un manque au niveau de la culture savante qu'il pointe.

Sur l'autre plan, les objets populaires pris en considération (télévision, défilé de la saint-Jean-Baptiste, Léandre Bergeron et autres) sont tous redevables de la même pensée critique orientée vers des questions d'aliénation, de carence flagrante de culture.

Quelques exemples sont nécessaires pour comprendre que la position de l'auteur est constamment en mouvement: devant l'objet populaire, devant l'effort d'inscription dans le continent, il se définit comme le dépositaire de la «grande culture», l'européenne (Il n'y a pas dans l'«Amérique» la ressource mentale pour concevoir l'autre..., p. 70), alors que devant les objets de culture savante, il parle au nom du nécessaire enracinement dans la culture d'ici (Bon, te v'la reparti à te comparer d̀ des gens des vieux pays, p. 115). Dans tous les cas, l'instance énonciatrice occupe une position frauduleusement critique, couverte par l'ironie facile, qui n'a en définitive comme fonction que d'assurer une position de pouvoir irrepérable: la distanciation n'est pas critique mais dogmatique, faute d'implication du sujet.

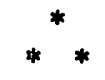

Le schéma d'inspiration lacanienne «imaginaire/réel/symbolique» sous-tend aussi ces essais, en fournissant une autre clef de lecture: la culture, lit-on, est essentiellement le fait de l'accès de la collectivité au symbolique, c'est-à-dire une structuration et une hiérarchisation des valeurs, à la possibilité d'une représentation de la société, alors qu'inversement, l'imaginaire renvoie aux pulsions de l'inconscient, à l'immédiateté de la perception, à l'enchaînement aux images archétypales.

Dans cette perspective, les lectures que fait Larose vont toutes dans le même sens: le Québécois a refusé l'accès au symbolique, au savoir structuré, à la pensée critique, soit pour se confronter directement à l'objet réel, soit pour «refouler» dans le lieu primitif de l'imaginaire 4 .

L'existence québécoise souffre d'une véritable disette de symbolique. La modernisation précipitée, l'obsession de «l'ouverture aux autres», l'idéalisation fiévreuse de l'entrepreneurship témoignent surtout de ce qui distingue votre [sic] détresse parmi celles des autres sociétés soumises à la vérité moderne. Les dernières années ont frappé de stérilité les rencontres, les paroles, les manières. Il manque la suite - le rappel, le symbole (p. 15-16). 
Ce passage termine un essai critique sur le Déclin de l'empire américain. L'auteur cherche ici à rendre compte du choix fait par les universitaires mis en scène pour le sexe contre le savoir. Au niveau du contenu de l'énoncé, la lecture est pertinente; seulement, le film, le scénario, la réflexion sur la position de l'intellectuel sont déjà un produit symbolique, une représentation: l'ambiguitté tient à ce que l'auteur condamne Arcand à se maintenir au niveau de la brutalité des gestes, à la puissance de l'ennui généré par des histoires interminables de sexe, au «manque de manières»; comme si ces images, cette thématique devaient faire sombrer, de façon irréversible, le film dans l'imaginaire.

Le mauvais goût, ou la «quétainerie», représente finalement chez Arcand le seul criterre de jugement. Profonde, existentielle même, la quétainerie inspire une sorte de dégoût paternaliste d̀ ceux qui ne sont pas quétaines (un peu comme les pauvres répugnent aux nouveaux riches) $(\mathrm{p} .9)^{5}$

En somme, il n'est question que de lieux d'énonciation qui déterminent des lieux de pouvoir: de quel droit le critique peut-il s'attribuer ainsi l'exclusivité de la lecture au second degré, de la pensée critique, des bonnes manières, des rencontres, du rappel, bref du symbolique? Le dérisoire, le manque de jugement d'un côté, le bon droit et le dégoût de l'autre?

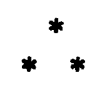

«FRAIS DE REPRÉSENTATION. Du Québec et de la France» constitue certes le texte le plus original, mais aussi le plus significatif de l'ambiguité entretenue: sont mis en scène l'ORAL et l'ÉCRIT qui entament un dialogue où se croisent ces deux codes, ces deux instances énonciatrices, l'une renvoyant à la culture populaire, l'autre à la savante, ou encore, l'une au symbolique, l'autre à l'imaginaire.

L'introduction prend comme pretexte l'hagiophone, ce filtre transparent placé dans les comptoirs publics, et chargé de protéger le préposé contre la transmission des virus. L'hagiophone constitue un symbole fort juste dans la mesure où il filtre la voix, s'interposant entre les deux interlocuteurs, médiatisant leur communication; l'hagiophone, c'est aussi, par extension, le délai, le détour de la communication par l'écrit, par les formes symboliques. Les deux voix qui parlent ici sont québécoises et ce qui est révélateur, c'est que l'ÉCRIT assume et défend l'usage de l'hagiophone importé de France, avec toutes ses connotations, alors que l'ORAL mise sur la spontanéité, le rapport direct entre les personnes:

L'ÉCRIT - ...quand je pense au texte inouï de Derrida, à Heidegger qui pense la pensée à la trace, a Hofmannsthal dénudant le désespoir dans un jardin de symboles...

L'ORAL-Bon, te v'la reparti d te comparer à des gens des vieux pays. 
L'ÉCRIT - Pas du tout! Tu es fou de folie! je ne me compare pas, j'envie une position poétique ou philosophique, un savoir vivre enchanté au milieu d'un jardin d'où la technique serait toujours sur le point de me chasser.

\section{L'ORAL — Un jardin a l'anglaise ou d la française? Libre ou pogné?}

Les Français font pousser les fleurs au cordeau, faut pas qu'un poil dépasse. (p. 115)

Le texte est cohérent, amusant même et, étonnamment, juste dans le ton: si ce n'est qu'il est étouffant, renvoyant le Québécois, face au Français, dans un statut de primitif ou de bûcheron n'ayant pas encore accédé à la culture.

Le sentiment d'étouffement que je ressens à la lecture vient de l'extrême codification du texte: l'oral renvoie à la culture populaire, québécoise, à l'imaginaire, au manque de raffinement, à la spontanéité, au NON référendaire, à l'appartenance au continent américain, alors qu'inversement, l'écrit renvoie de façon manichéenne aux valeurs opposées. Comme si en France, la communication orale n'existait pas, comme si la culture institutionnalisée était protégée contre tout retour de l'imaginaire, comme si... Ce qui est étouffant, c'est cette accumulation de schémas binaires où, malgré l'ironie évidente, il n'y a plus place pour la nuance, pour le jeu des connotations, en somme pour la liberté du sujet de tout simplement imaginer, symboliser, se rapprocher du réel.

Il y a plusieurs années, Umberto Eco décrivait ce mécanisme de schématisation binaire à outrance à propos de Ian Fleming, l'auteur des James Bond:

La construction par schéma, la bipartition manichéenne est toujours dogmatique, intolérante. Le démocrate est celui qui refuse les schémas et qui reconnaît les nuances, les distinctions et justifie les contradictions. Fleming est réactionnaire comme l'est d̀ sa source la fable, toute fable. C'est l'esprit conservateur, ancestral, domestique et statique des fables et des mythes qui transmettent une sagesse élémentaire, construite et transmise par un simple jeu de lumieres et d'ombres et la transmettent par des images indiscutables ne permettant pas la critique. Si Fleming est fasciste, il l'est parce que c'est le propre du fascisme que d'être incapable de passer de la mythologie d la raison, que de tendre a gouverner en se servant de mythes et de fétiches. 6

À la limite, cette schématisation se referme sur les images parentales: le texte se termine sur cette représentation du retour à la mère:

L'ORAL - ... Concentre-toi sur le grand vide intérieur de la vraie vie au centre de toi-même, ferme les yeux, c'est ça, cool down, dors. On parlait jusse pour parler, dors, maman est ld! (p. 117)

À la série des valeurs rattachées à la culture populaire, il faudrait donc 
ajouter cette fixation libidinale à la mère interdisant précisément l'accès au symbolique 7 . La France serait-elle devenue notre Père patrie?

Il y a quelques années, André Belleau reprochait à l'intellectuel québécois de réagir à des signaux plutôt que d'interpréter des signes. Cette proposition, venant précisément de cette autorité que cite Larose, me laisse songeur lorsque je lis la «lettre à une amie» s'adressant à une canadienne d'origine à laquelle il est conseillé de ne pas revenir au pays. La lettre se termine sur un ton plus personnel:

Pour moi, tu le sais puisque nous avons voyagé ensemble, je cache autant que possible ma nationalité canadienne pour ne pas passer pour un épais. Si tout marche comme je l'espère, j'en serai bientôt débarrassé. (p. 204)

Le propos et le projet sont cohérents avec les essais précédents. Si ce n'est que personnè n'y croira. On n'aura pas construit un tel discours, élaboré minutieusement une telle rhétorique permettant la plus grande aisance énonciatrice, la plus grande liberté, et qui plus est, exclusive, pour quitter ainsi, sans raison en fait!

Ce faux adieu est fidèlement reproduit sur la page couverture illustrant l'auteur devant le pays de neige, nous tournant le dos, mais, par le mouvement du cou, détournant les yeux du pays pour nous regarder. Cette double torsion (renvoyant autant à la rhétorique du texte qu'à l'hagiophone) est confortablement compensée par le bonnet de fourrure du pays. J'imagine que c'est ce bonnet de fourrure que la gouverneure générale a voulu reconnaître. Quoi d'autre autrement?

1 Jean Larose, la Petite Noirceur, Montréal, Boréal, 1987, 204 p.

2 Jean Baudrillard, À l'ombre des majorités silencleuses, Paris, Denoël / Gonthier, coll. «Médiations», $\mathrm{n}^{\circ} 226$.

3 Ce texte est particulièrement intéressant dans la mesure où ce sont trois périodiques culturels, la Nouvelle Barre du jour, Voix \& images et Liberté, leur mode d'intervention dans la culture, leurs appartenances idéologiques qui sont mis en scène et confrontés.

4 Rappelons que la monographie que Larose avait consacrée au poète Nelligan (le Mythe Nelligan, essai, 1981) reposait essentiellement sur la même problématique et la même pensée critique.

5 La parenthèse est évidemment de l'auteur.

6 Umberto Eco, «James Bond: une combinatoire narrative», Communication, 8, Paris, Seuil, 1966, p. 92.

7 Un essai intitulé «Le féminisme masculin», inscrivant la problématique de la réaction des hommes québécois au féminisme, reprend cette question d'une façon troublante. 